\title{
A dupla face da velhice: o olhar de idosos sobre o processo de envelhecimento
}

Recebido em: 12/06/2012

Aceito em: 30/01/2013

\author{
Dayse Layanne Pereira Meneses \\ Fernando José Guedes da Silva Júnior ${ }^{2}$ \\ Hayanna de Sousa Ferreira Melo ${ }^{3}$ \\ Jaqueline Carvalho e Silva 4 \\ Vera Lúcia Evangelista de Sousa Luz ${ }^{5}$ \\ Maria do Livramento Fortes Figueiredo ${ }^{6}$
}

O crescimento da população idosa no Brasil aponta demandas para o autocuidado. Objetivou-se com este estudo descrever e analisar o significado da velhice para 12 idosos de ambos os sexos, cadastrados em um Centro de Convivência no município de Teresina-PI. Os dados foram coletados por meio de entrevistas abertas, gravadas e transcritas na íntegra. A análise temática possibilitou a formulação de duas categorias: a velhice como sinônimo de felicidade, união familiar e experiência de vida; bem como significados negativos de doença, solidão e tristeza. Conclusão: Para esses idosos, a velhice tem duplo significado: positivo e/ou negativo.

Descritores: Significado, Envelhecimento, Enfermagem.

\section{The two sides of aging: the elderly people's view of the aging process}

The growth of the older population points out the need for self-care. This study aimed to describe and analyze the meaning of aging for 12 elders of both sexes, enrolled in a Conviviality Center, in the municipality of Teresina-PI. The data were collected through open interviews, which were fully recorded and transcribed. From the theme analysis, two categories could be formulated: aging as a synonym for happiness, family unity, and life experience, as well as negative meanings such as diseases, solitude, and sadness. Conclusion: For those elders, aging has a double meaning; positive and/ or negative.

Descriptors: Meaning, Aging, Nursing.

\section{Las dos caras de la vejez: la visión de los ancianos sobre el proceso de envejecimiento}

El crecimiento de la población anciana en Brasil señala demandas para el autocuidado. Se buscó con este estudio describir y analizar el significado de la vejez para 12 ancianos de ambos sexos, registrados en un Centro de Convivencia, en el municipio de Teresina-PI. Los datos fueron colectados por medio de entrevistas abiertas, grabadas y transcriptas integralmente. El análisis temático hizo posible la formulación de dos categorías: la vejez como sinónimo de felicidad, unión familiar y experiencia de vida; así como también significados negativos de enfermedad, soledad y tristeza. Conclusión: Para estos ancianos la vejez tiene un doble significado: positivo y/o negativo.

Descriptores: Significado, Envejecimiento, Enfermería.

\section{INTRODUÇÃO}

$\mathrm{O}$ Brasil está vivenciando um processo de transição que mudou o perfil demográfico do país. Com o avanço do sistema de saúde e as melhorias nas condições gerais de vida, a população está alcançando a longevidade e, consequentemente, o país está envelhecendo. Estima-se que a expectativa de vida da população brasileira poderá alcançar os 75,5 anos e será formada por 7,7\%, ou seja, 16,2 milhões de idosos em $2020^{(1)}$.

Devidoaessecrescimentoda populaçãoidosa,surgenoBrasil uma consciência davelhice comoumfatordeordem social, pois o envelhecer diz respeito a uma fase de mudança bio-psico-sócio-cultural que faz parte da vida de cada pessoa ${ }^{(2)}$. Assim, é um momento em que o idoso reflete sobre sua própria existência e percebe que, apesar de ter alcançado seus objetivos, sofreu muitas perdas das quais a saúde se torna a mais afetada.

Nesse sentido, o envelhecimento pode ser compreendido como um fenômeno biológico, que envolve a perda da capacidade funcional necessária para a realização das atividades de sua vida diária. Entretanto, devem ser

1 Acadêmica de Enfermagem do Centro de Ensino Unificado de Teresina-CEUT. Teresina. Piauí. Email: dayselanny_7@hotmail.com

2 Enfermeiro. Mestrando em Enfermagem da Universidade Federal do Piauí (UFPI). Teresina. Piauí.

3 Graduanda em Enfermagem do Centro de Ensino Unificado de Teresina-CEUT. Teresina. Piauí.

4 Enfermeira. Mestre em Enfermagem pela Universidade Federal do Piauí (UFPI). Docente da Faculdade de Saúde, Ciências Humanas e Tecnológicas do Piauí-NOVAFAPI. Teresina. Piauí.

5 Enfermeira. Especialista em Enfermagem pela Universidade Federal do Piauí (UFPI). Docente do Centro de Ensino Unificado de Teresina-CEUT. Teresina. Piauí.

6 Enfermeira. Doutora em Enfermagem. Docente da Universidade Federal do Piauí (UFPI). Teresina. Piauí. 
levadas em conta as mudanças naturais desse processo. Assim, o envelhecimento bem-sucedido está associado a uma importante mudança ideológica que não considera a velhice como sinônimo de perda, doença, inatividade e algo contrário ao desenvolvimento(1).

De acordo com o que foi citado, o Ministério da Saúde (MS) adotou diretrizes básicas que estão inseridas na Política Nacional de Saúde da Pessoa Idosa (PNSPI), que se preocupa com a promoção do envelhecimento saudável, com a prevenção de doenças e a manutenção da capacidade funcional. Essas diretrizes preconizam ainda, atenção integral e integrada à saúde da pessoa idosa, recursos para a promoção da qualidade à atenção à saúde, divulgação e informação sobre as políticas de saúde para os profissionais de saúde e usuários, além do apoio aos estudos e pesquisas(1).

Devido à melhoria das condições de vida, a expectativa de vida da população vem crescendo e, consequentemente, a população de idosos aumenta, indicando assim a necessidade de formas alternativas de participação e de convívio na sociedade. Nesse contexto, surgem os Centros de Convivência como locais destinados a proporcionar à pessoa idosa permanência diurna, oferecendo atividades e propostas diferenciadas com espaço para o lazer, sociabilidade, cultura, atividades associativas e educação para a cidadania ${ }^{(3)}$.

Dessa forma, os Centros de Convivência surgem para os idosos como importantes locais de convívio social, lazer e melhoria da qualidade de vida, contribuindo para melhor compreensão e esclarecimentos dos aspectos psicossociais. Assim, este estudo teve por objetivos descrever e analisar o significado da velhice para idosos cadastrados em um Centro de Convivência.

\section{METODOLOGIA}

Trata-se de um estudo exploratório com abordagem qualitativa. Os sujeitos foram 12 idosos de ambos os sexos, cadastrados no Centro de Convivência do Parque Piauí no município de Teresina-PI, que aceitaram participar da pesquisa. O projeto da pesquisa foi analisado e aprovado pelo Comitê de Ética em Pesquisa da Faculdade de Saúde, Ciências Humanas e Tecnológicas do Piauí - NOVAFAPI com CAAE de número 0269.0.043.000-11.

A coleta de dados deu-se no período de 31/8/2011 a 9/9/2011, por meio da técnica de entrevista aberta. Utilizouse a análise temática que consiste em três etapas: pré-análise, exploração do material e tratamento dos resultados ${ }^{(4)}$.

\section{ANÁLISE E DISCUSSÃO DOS DADOS}

Após a análise dos dados foram formuladas duas categorias temáticas referentes aos significados da velhice para os idosos participantes do estudo, quais sejam: Feliz Idade, categoria representada por sentimentos positivos, de maior tranquilidade financeira, liberdade, união familiar, com mais solidariedade e compartilhamento de experiências de vida, e Lidando com as Perdas, categoria em que a velhice foi considerada com um momento de perdas decorrente de doenças, solidão e tristeza, tendo, portanto, um significado negativo.

\section{Feliz idade}

Ter uma boa velhice significa viver um processo contínuo de adaptações e aprendizagem, onde se tem perdas e ganhos, obtenção de experiências, vivências e uma busca constante de integridade e bem-estar(5). É a partir desse princípio que a vida de uma pessoa idosa pode tornar-se de uma grande riqueza interior, incluindo o autoconhecimento e a autoaceitação com qualidade que podem ser adquiridas ao longo da vida(6).

Sem dúvida, as pessoas que alcançaram os 60 anos e mais acumularam ao longo de suas vidas ricas experiências de significações diversificadas, com saberes e atitudes que possibilitam trocas e estabelecimento de novas relações positivas, inclusive com os mais jovens. Essas vivências são traduzidas em ganhos e oportunidades, dando um significado de felicidade, união familiar, experiências e sabedoria(7), como se evidencia nos depoimentos abaixo:

[...] para mim, a velhice está sendo um momento de felicidade, porque apesar de ter problemas, ainda estou muito feliz. (Depoente 06)

[...] Para mim, velhice, graças a Deus, eu não sei nem o que é. O ritmo que eu tinha de nova nunca perdi. É maravilhoso, eu me sinto muito bem, muito bem, maravilhosamente bem mesmo. (Depoente 07)

[...] É uma coisa maravilhosa, fiz 60 anos no dia 10 de julho, para mim foi ótimo. E agora está tudo bem, graças a Deus. Eu estou com a vida melhor do que antes. (Depoente 10)

[...] Velhice é tudo de bom, porque já passou a fase nova, e eu tenho assim, como se diz, um orgulho de ser velho, de ser idoso. Eu estou satisfeito com minha idade. (Depoente 11) Portanto, para esses idosos que apresentaram significados tão positivos para esta fase de suas vidas, observa-se a importância da incessante busca da felicidade a partir de um cotidiano com objetivos e novos projetos, além da contínua luta por uma vida saudável com autonomia e independência para o autocuidado.

Para que os idosos superem as dificuldades biopsicossociais pertinentes à velhice, mostra-se necessário o envolvimento dos mesmos em diversas tarefas, dentre as quais destacamse as comunitárias, as socioeducativas e as de $\operatorname{lazer}^{(8)}$.

Nessa perspectiva, pode-se perceber que a felicidade para estes sujeitos está relacionada à aceitação da sua própria idade. Contudo, é importante ressaltar que são vários 
os fatores que influenciam o bem-estar do idoso, dentre os quais estão a família, que representa um verdadeiro símbolo de confiança e proteção. A boa convivência e as relações interpessoais são importantes e essenciais, pois assim eles se sentem aceitos e acolhidos(9).

Dessa forma, os idosos relatam a importância da interação familiar para uma velhice bem-sucedida, fato ilustrado nos depoimentos a seguir:

[...] meus filhos todos já estão casados, têm as suas famílias, mas não me abandonaram, graças a Deus. (Depoente 01)

[...] eu vou para onde eu quero, estou com minhas filhas, tenho as minhas amizades. (Depoente 02)

[...] eu vivo com a minha família. Graças a Deus, me sinto muito acolhida por ela. (Depoente 05)

Nesse contexto, a família torna-se indispensável para garantia de felicidade desse idoso, independente da forma em que ela esteja estruturada. Logo, é através dela que o idoso vivencia grande parte de sua experiência de vida, onde se tem a reconstrução da sua história e a ligação remota com o passado.

No que diz respeito às experiências e vivências dos idosos, observa-se que os saberes e atitudes na velhice resultaram de conhecimentos e práticas diárias desenvolvidas no ciclo vital - ou seja, infância, adolescência, vida adulta até a fase atual, com um desempenho de sucesso e prazer em muitas atividades e a superação de momentos de dificuldades para outras tarefas, como se pode observar nos depoimentos abaixo:

[...] o bom é que é experiência de vida, nós somos um bauzinho de surpresa, nós somos como uma águia e renovamos a cada momento. (Depoente 04)

[...] é bom ser idoso, porque idoso já tem experiência, é bom. (Depoente 09)

A velhice representa um momento de compartilhamento das experiências de vida e de conhecimentos acumulados ao longo dos anos. Essa maneira positiva de vivenciar a velhice possibilita aos idosos oportunidades contínuas de saúde, participação na sociedade e seguridade. O olhar do idoso a respeito de uma velhice bem-sucedida está diretamente relacionado ao bem-estar físico e mental(10). Dessa forma, reconhece-se que a velhice pode ser um período prazeroso, e embora esteja explicitamente ligada à qualidade de vida, pode também ser um período de liberdade, independência e experiência acumulada.

\section{Lidando com as perdas}

A velhice é um processo complexo de alteração na trajetória de vida das pessoas. A repercussão do envelhecimento é compreendida de maneira diferente, dependendo da história de vida pessoal, do suporte familiar e do estilo de vida adotado por cada um. Dessa forma, o idoso fica mais suscetível às perdas evolutivas em vários domínios e na multidimensionalidade de cada indivíduo.

Nesse contexto, esta categoria aborda os significados negativos atribuídos à velhice pelos idosos, relativos às perdas biológicas, emocionais e sociais:

[...] a gente vai ficando velha, vai tendo dor nos ossos

[...] a gente fica toda dolorida, mas ainda trabalha, né? (Depoente 03).

[...] A velhice não é coisa muito boa [...] eu mesmo já fiz quatro pontes de safena e já me deu um derrame, AVC [...] (Depoente 08).

[...] Para mim não está bem bom, não. Para mim, se eu tivesse com saúde [...] era para eu ter feito uma cirurgia das veias, pois tenho três veias entupidas. (Depoente 12).

Desde os primórdios, a velhice sempre foi associada a doenças, perdas e limitações, sob influência do modelo biomédico, estigmatizando essa fase como um período de decadência e perdas. Infelizmente, ainda hoje essa visão negativa se confirma como demonstraram os depoimentos acima, pois as doenças e alterações físicas determinam o significado negativo para o envelhecimento, que repercutem em baixa autoestima para os idosos, principalmente pela possibilidade de se tornarem dependentes ou por não poderem exercer suas atividades rotineiras ${ }^{(11)}$.

Há uma relação de reciprocidade entre velhice e doença tão enraizada, que fica difícil lembrar que doença é uma consequência de hábitos adquiridos, e que pode acontecer em qualquer idade e com qualquer pessoa(12).

A partir dos relatos, pode-se perceber que a relação de velhice com doença está direcionada às limitações que os idosos encontram e pelo medo de não poderem exercer suas atividades diárias, de se tornarem dependentes pela doença e não obter o apoio da família, gerando sentimentos como solidão e tristeza, também inseridas nesta categoria e observadas nos relatos a seguir:

[...] eu tenho muito medo da solidão. (Depoente 01).

[...] aí os filhos vão saindo, vão trabalhando, todo mundo ocupado, e a gente fica só [...](Depoente 03).

Os idosos investigados associaram a velhice à solidão e à tristeza, principalmente pelo medo do abandono ou por viverem sozinhos. Esses sentimentos ampliam o risco desses idosos necessitarem de suporte técnico assistencial nesta fase de suas vidas. Daí a importância da inserção dos idosos em grupos de apoio, em ações socioeducacionais e recreativas, em espaços tais como os Centros de Convivência, que favorecem a minimização do adoecimento decorrente de solidão, tristeza, desamparo ou simplesmente pela falta de comunicação.

Estudos realizados com idosos, principalmente com os que moram sozinhos, indicam índices muito elevados de 
insatisfação com a velhice, pois associam a infelicidade, o abandono e a solidão ao fato de ser idoso ${ }^{(13)}$.

O sentimento de tristeza e solidão frequentemente está relacionado ao luto, decorrente do falecimento de um dos cônjuges, e acomete principalmente mulheres, que ficam viúvas em maior proporção. Esses sentimentos negativos podem agravar-se e determinar sintomas de um quadro depressivo, associando-se a debilidade física, fragilidade emocional e dificuldades nas relações familiares e sociais ${ }^{(14)}$.

Os idosos deste estudo abordaram a solidão como um sentimento presente em suas vidas. E consideraram a companhia da família e dos amigos como indispensáveis para enfrentá-la. Os vínculos sociais são de fundamental importância para manter a alegria das pessoas, principalmente dos idosos. Já o rompimento das relações interpessoais altera as defesas orgânicas, deixando as pessoas, especialmente as idosas, mais suscetíveis a doenças, tanto na dimensão física, como na mental e social(15).

\section{CONCLUSÃO}

Assim, conclui-se que para os idosos participantes deste estudo a velhice ora assume um significado positivo, enfatizando que a felicidade, a união familiar e a experiência de vida são sinônimos de um envelhecer bem-sucedido, ou representa-se de forma negativa como doença, solidão e tristeza, decorrentes das perdas e da presença de sintomas físicos e/ou emocionais que são agravados pela fragilidade das relações familiares e sociais.

Esses significados apontados pelos idosos investigados poderão contribuir para uma melhor atuação dos profissionais de saúde, com destaque para o enfermeiro, a partir de ações socioeducativas que favoreçam o bem-estar, a autonomia e independência dos idosos.

\section{Referências}

1. Ministério da Saúde (BR). Secretaria de Atenção à Saúde. Departamento de Atenção Básica. Caderno de Atenção Básica: envelhecimento e saúde da pessoa idosa. Brasilia: Ministério da Saúde; 2006.

2. Mendes MRSSB, Gusmão JL, Faro ACM, Leite RCBO. A situação social do idoso no Brasil: uma breve consideração. Acta Paul Enferm. 2005;18(4):422-6.

3. Ministério da Saúde (BR). Decreto n 1.948, de 3 de julho de 1996. Dispõe sobre a Política Nacional do Idoso. Brasilia: Ministério da Saúde; 1996.

4. Minayo MCS. Pesquisa social: teoria, método e criatividade. $26^{\mathrm{a}}$ ed. Petrópolis: Vozes; 2007.

5. Neri AL. Qualidade de vida no adulto maduro: interpretaçōes teóricas e evidências de pesquisa. Campinas: Papirus; 2000.

6. Sad I. Revisão de vida, autoconhecimento e autoaceitação: tarefas da maturidade.

In: Neri AL. Desenvolvimento e envelhecimento: perspectivas biológicas, psicológicas e sociológicas. São Paulo: Papirus; 2001. p. 53-69.

7. Debert GG. A reinvenção da velhice: socialização e processos de reprivatização do envelhecimento. São Paulo: EDUSP; 2002.

8. Witter GP, organizador. Envelhecimento: referências teóricas e pesquisas. Campinas: Alínea; 2006.
9. Boutique NC, Santos RL. A. Aspectos socioeconômicos do envelhecimento. In: Papaléo Netto M. Gerontologia: a velhice e o envelhecimento em visão globalizada. São Paulo: Atheneu; 2002. p. 136-53.

10. Caldas PC. Memória, trabalho e velhice: um estudo das memórias de velhos trabalhadores. Terceira idade desafio para o terceiro milênio. Rio de Janeiro: Relumé Dumará; 2003.

11. Garrido R, Menezes PR. O Brasil esta envelhecendo: boas e más notícias por uma perspectiva epidemiológica. Rev Bras Psiquiat. 2002;24(spe):3-6.

12. Blessmann EJ. Corporeidade e envelhecimento: o significado do corpo na velhice. Estud Interdiscip Envelhec. 2004;6(1):21-39.

13. Capitanini MES, Neri AL. Sentimentos de solidão, bem-estar subjetivo e

relações sociais em mulheres idosas vivendo sozinhas. In: Neri AL, Yassuda MS,

Neto F. Velhice bem-sucedida: aspectos afetivos e cognitivos. Campinas: Papirus; 2004. p.71-89.

14. Pedrozo SK, Portella MR. Solidão na velhice: algumas reflexões a partir da compreensão da um grupo de idosos. Bol Saúde. 2003;17(2):171-83.

15. Leite MT, Battisti IED, Berlezi EM, Scheuer AI. Idosos residentes no meio urbano e sua rede de suporte familiar e social. Texto Contexto Enferm. 2008;17(2):52-7. 